\title{
Accordion-like Effect of Flexible Organic Structure-Directing Agents in the Synthesis of Ferrierite Zeolite
}

\author{
Ramon K.S. Almeida ${ }^{a, b, \neq}$, Joaquín Peréz-Pariente, ${ }^{a}$ and Luis Gómez-Hortigüela ${ }^{a, *}$
}

aInstituto de Catálisis y Petroleoquímica, ICP-CSIC, C/ Marie Curie 2, 28049 Madrid, Spain.

${ }^{b}$ Institute of Chemistry, University of Campinas, Rua Monteiro Lobato, 270, 13084-861 Campinas, SP, Brazil.

${ }^{¥}$ Current address: Academic Unit of Serra Talhada, Federal Rural University of Pernambuco, UAST-UFRPE, Av. Gregório Ferraz Nogueira, S/N, 56909-535 Serra Talhada, PE, Brazil

*Corresponding author. E-mail address: lhortiguela @icp.csic.es (L. Gómez-Hortigüela)

\begin{abstract}
Ferrierite zeolite was synthesized by a co-structure-directing route using a highly flexible diquaternary ammonium cation ( $N, N^{\prime}$-bistriethylpentanediyldiammonium) as a structure directing agent in combination with tetramethylammonium as a small co-structure-directing agent. Strong alterations of the ${ }^{13} \mathrm{C}$ NMR bands of the bulky organic dication upon confinement within the ferrierite framework suggest a change of conformation driven by host-guest interactions. A combination of molecular mechanics and DFT calculations of the theoretical ${ }^{13} \mathrm{C}$ NMR chemical shifts allowed to explain the observed differences in the NMR bands of the dication in solution and when hosted in ferrierite: upon confinement, the flexible dication needs to squeeze through the flexible pentyl chain which locates along the 10MR ferrierite
\end{abstract}


channels in order to host the two bulky triethyl ammonium groups in adjacent intersections with 8MR channels. Our work suggests that highly flexible cations, usually considered as less convenient organic structure-directing agents because of low specificity, have the advantage of being able to properly fit with different zeolite cell dimensions through an accordion-like effect by squeezing or stretching their flexible chains.

KEYWORDS: conformational space; zeolite; NMR; organic structure-directing agents; flexibility.

\section{INTRODUCTION}

In recent years, very interesting discoveries have been made in finding new zeolite materials through the use of a wide range of organic cations as structure-directing agents (SDA) [1]. Diquaternary ammonium cations with the general formula $\mathrm{R}_{3} \mathrm{~N}^{+}\left(\mathrm{CH}_{2}\right)_{n} \mathrm{~N}^{+} \mathrm{R}_{3}$ were originally used as SDA by Casci and coworkers, who obtained several zeolites (including EUO and NES frameworks) by using hexamethonium and decamethonium $\left(\left(\mathrm{CH}_{3}\right)_{3} \mathrm{~N}^{+}\left(\mathrm{CH}_{2}\right)_{n} \mathrm{~N}^{+}\left(\mathrm{CH}_{3}\right)_{3}\right.$ with $\mathrm{n}=6$ and 10 , respectively) [2-4]. The phase selectivity of these bulky and flexible $\mathrm{R}_{3} \mathrm{~N}^{+}\left(\mathrm{CH}_{2}\right)_{n} \mathrm{~N}^{+} \mathrm{R}_{3}$ dications towards different zeolite materials strongly depends on the length of the polymethylene chain, the nature of the ' $R$ ' alkyl group, the type of framework heteroatoms and the mineralizing agent $\left(\mathrm{OH}^{-}\right.$or $\left.\mathrm{F}^{-}\right)[5,6]$. It has been shown that the use of SDAs in zeolite synthesis with a high degree of flexibility, instead of conformationally-rigid and bulky species, is a viable strategy for the discovery of previously unobserved framework structures [7]. Indeed, the high flexibility characteristic of these cations, and the large conformational space associated to the alkyl 
spacers, has enabled the crystallization of a wide range of zeolite materials from small to extra-large pore materials [8-11]. These flexible cations have the advantage of having a high probability of leading to zeolite materials under conventional synthesis conditions due to their large conformational space available, providing upon simple rotations of the flexible alkyl chain a set of conformers with very different size and shape, all being potentially able to direct the crystallization towards a particular zeolite framework [7]. However, this is in detriment of the host-guest specificity due to the large number of distinct host-guest pairs potentially available. In this context, $\mathrm{R}_{3} \mathrm{~N}^{+}\left(\mathrm{CH}_{2}\right)_{n} \mathrm{~N}^{+} \mathrm{R}_{3}$-type cations have proved very efficient for the synthesis of zeolite materials, being able to drive the crystallization of a number of different zeolite structures. To cite some examples, materials like ZSM-48, MTW, BEA, MFI, ITH, AST, MTN and RUT have been prepared in fluoride media [12], and ERI, *MRE, MAZ, MTW, EUO, MTT and MWW in alkaline media [13,14]. Moreover, the use of these flexible cations is interesting also for discovering new frameworks, as demonstrated by the use of hexamethonium that led to the crystallization of zeolites with ITH, IWW, IWR and the new ITQ-33 (ITT), with extra-large $18 \mathrm{MR}$ pores $[7,15]$. Similarly, Camblor and coworkers have intensively studied the use of flexible bis-imidazolium dications with different lengths of the intermediate alkyl chain, and several interesting zeolite materials have been found as a function of the separation between imidazolium rings [16-18].

One efficient flexible diquaternary ammonium cation is $N, N^{\prime}$-bis-triethyl-pentanediyldiammonium, which was able to direct the crystallization of a number of zeolites depending on the composition of the synthesis gels, including P1 (GIS), SSZ-16 (AFX), SUZ-4 (SZR), ZSM-57 (MFS) and mordenite (MOR) [19]. This suggests that the structure-directing ability of this SDA is not strong enough itself to govern the synthesis 
of a specific zeolite. Due to the geometric constraints imposed by the pore structures, this diquarternary cation occluded within the crystallized materials should adopt different conformations, which in turn provides the main phase selectivity factor. Thus, it would be expected that the type of conformations of such a flexible dication should differ according to the nature and extent of interactions between the SDA and the surrounding inorganic species in the synthesis gel [20].

Apart from the use of single diquaternary ammonium cations as SDAs, we have in the last decade proposed a new synthesis strategy [21-24] where a combination of two different organic species of different size are simultaneously used as co-structure directing agents (co-SDA). This strategy facilitates the production of zeolite structures with complex systems of channels and/or cavities with dimensions suitable to host each organic species as a function of their structural/geometrical relationship. If appropriate synthesis conditions are found, the presence of these two co-SDAs in the synthesis gel can potentially modify the nucleation and crystallization pathway towards complex frameworks, thus allowing the crystallization of phases other than those prepared using the isolated species. As an example, we recently prepared ferrierite zeolite from the combination of a bulky diquaternary ammonium dication (1,6-bis(N-methylpyrrolidinium)hexane) and a small cation (tetramethylammonium) as co-SDAs [24]. In this work, our primary objective was to explore the crystallization of zeolite materials in fluoride medium by using the flexible and bulky diquaternary ammonium cation, $N, N^{\prime}-$ bis-triethylpentanediyldiammonium, together with small co-structure directing agents, pyrrole, tert-butylamine or tetramethylammonium. Under certain conditions, this flexible dication led to the crystallization of pure ferrierite materials, which are interesting because of their use in the chemical industry for the isomerization of n-butene [25]. 
A number of recent works [16,26-29] have shown the importance of the conformational space of flexible organic cations when directing the crystallization of zeolitic materials. Interestingly, we have observed that a combination of experimental ${ }^{13} \mathrm{C} \mathrm{NMR}$ spectroscopy of the organic species in solution and confined within microporous frameworks with theoretical DFT-based predictions of the ${ }^{13} \mathrm{C}$ chemical shifts is extremely useful for unraveling changes of conformation upon confinement that provide very interesting insights into the structure-directing effect of flexible cations. Thus, in this work we apply the same methodology in order to understand the conformational space of the flexible organic dication used when confined within the zeolite framework obtained.

\section{EXPERIMENTAL AND COMPUTATIONAL DETAILS}

\subsection{Synthesis of $\mathbf{N}, \mathrm{N}^{\prime}$-bis-triethylpentanediyldiammonium}

The dibromide $N, N^{\prime}$-bis-triethylpentanediyldiammonium $\left(\mathrm{Et}_{6} \mathrm{DQ}_{5}\right)$ cation was prepared by reacting 1,5-dibromopentane (Aldrich, $98 \%$ ) with an excess $(50 \%)$ of triethylamine (Aldrich, $99 \%$ ) in acetone as solvent in a procedure similar to that described in [19]. In a typical procedure: $67.5 \mathrm{~g}$ of 1,5-dibromopentane (Aldrich, $98 \%$ ) was added to a solution of $82.7 \mathrm{~g}$ of triethylamine (Aldrich, $98 \%$ ) in $500 \mathrm{~mL}$ of acetone in a round-bottomed flask. The reaction was kept under strong stirring and reflux at $50{ }^{\circ} \mathrm{C}$ for 5 days. The $\mathrm{Et}_{6} \mathrm{DQ}_{5}$ ammonium dibromide salt was recovered by filtration and the excess amine and possible remains of 1,5-dibromopentane were removed by exhaustive washing with acetone; the purity of the product was verified by liquid ${ }^{1} \mathrm{H}$ NMR (Fig. S1 in the Supporting Information). The final dibromide salt (yield $67 \%$ ) was exchanged into the hydroxide form with an anionic resin (Amberlite IRN-78, Aldrich), and the solution was titrated with $\mathrm{HCl}(0.1 \mathrm{~N}$, Panreac) using phenolphthalein as an indicator. 


\subsection{Zeolite synthesis}

Zeolite samples were synthesized in fluoride medium from synthesis gels in which the molar ratios SDA/(T atoms) were kept constant. The molar composition of the synthesis gels was: (1-2x) $\mathrm{SiO}_{2}: x \mathrm{Al}_{2} \mathrm{O}_{3}: y \mathrm{HF}:(0.54-z) \mathrm{Et}_{6} \mathrm{DQ}_{5}(\mathrm{OH})_{2}: z$ co-SDA $: 5.6 \mathrm{H}_{2} \mathrm{O}$, where $x$ was $0.0312,0.0454$ or 0.0555 to yield $\mathrm{Si} / \mathrm{Al}$ ratios in the gel of 15,10 and 8 , respectively; $y$ was adjusted in each case to keep the charge balance. In particular synthesis gels, HF was added in excess to lower the $\mathrm{pH}$ to around 9, as shown in Table 1 (indicated by EHF, for excess $H F)$. $z$ was 0 for samples prepared with $\mathrm{Et}_{6} \mathrm{DQ}_{5}(\mathrm{OH})_{2}$ as the only SDA (Et $\left.\mathrm{DQ}_{5}\right)$, and 0.135 (0.405SDA:0.135co-SDA) or 0.27 (0.27SDA:0.27co-SDA) for samples prepared in the presence of co-SDAs, keeping the molar ratio (SDA+co$\mathrm{SDA}) /(\mathrm{Si}+\mathrm{Al})$ equal to 0.54 . The co-SDAs used were tetramethylammonium hydroxide (TMAOH, 25\% in water, Aldrich), pyrrole (Aldrich, $98 \%$,) and tert-butylamine (Aldrich, $98 \%)$

In a typical preparation of a synthesis gel, tetraethylorthosilicate (TEOS, Merck, $98 \%$ ) and aluminum isopropoxide (Aldrich, $98 \%$ ) were added to an aqueous solution containing the two SDAs, $N, N^{\prime}$-bis-triethylpentanediyldiammonium dihydroxide and tetramethylammonium hydroxide. The solution was stirred at room temperature to evaporate the alcohols coming from the hydrolysis of TEOS and $\mathrm{Al}$ isopropoxide and the excess of water to reach the desired composition. Subsequently, HF (Aldrich, $48 \%$ ) was added dropwise and the resulting thick gel was thoroughly homogenized and loaded into $20 \mathrm{~mL}$ Teflon-lined stainless steel autoclaves that were heated statically at $160{ }^{\circ} \mathrm{C}$ and autogenous pressure for 14 days. The solid products were recovered by filtration, washed with water and ethanol and dried at room temperature overnight. 
The samples will be denoted making reference first to the molar composition of the organic species employed as SDAs, specifying which of these species were used, second to the $\mathrm{Si} / \mathrm{Al}$ molar ratio in the syntheses gel and, finally, a reference to those cases where HF was added in excess (EHF).

\subsection{Characterization}

Solid products were characterized by X-Ray Diffraction (PANalytical X'Pert PRO MPD diffractometer) using $\mathrm{CuK} \alpha$ radiation. Thermogravimetric analyses were carried out using a Perkin-Elmer TGA7 instrument at a heating rate of $10{ }^{\circ} \mathrm{C} / \mathrm{min}$ under air flow and a temperature range of $25-900{ }^{\circ} \mathrm{C}$. CHN chemical analyses were carried out with a PerkinElmer $2400 \mathrm{CHN}$ analyzer. Si and Al contents were obtained with an ICP-OES Optima 3300 DV Perkin-Elmer. Solid-State ${ }^{29} \mathrm{Si},{ }^{27} \mathrm{Al}$ and ${ }^{13} \mathrm{C}$ MAS NMR spectra were performed on a Bruker AV 400 spectrometer using a BL4 probe; the rotation speed was $10 \mathrm{KHz}$ in all cases. ${ }^{1} \mathrm{H}$ to ${ }^{13} \mathrm{C}$ cross-polarization spectra were recorded using $\pi / 2 \mathrm{rad}$ pulses of 2.75 $\mu \mathrm{s}$, a contact time of $3 \mathrm{~ms}$ and a recycle delay of $4 \mathrm{~s}$. High-power decoupled (HPDEC)

${ }^{29} \mathrm{Si}$ spectra were acquired using pulses of $4.5 \mathrm{~ms}$ to flip the magnetization $\pi / 2 \mathrm{rad}$ and a recycle delay of $60 \mathrm{~s} ;{ }^{27} \mathrm{Al}$ spectra were measured using pulses of $0.4 \mathrm{~ms}$ to flip the magnetization $\pi / 30 \mathrm{rad}$ and delays of $0.5 \mathrm{~s}$.

\subsection{Computational Details}

A combination of molecular mechanics and DFT calculations was performed in order to understand the structure-directing effect of the flexible $\mathrm{Et}_{6} \mathrm{DQ}_{5}$ dication. We knew from previous works that TMA locates within the ferrierite cavities, developing a strong directing effect towards this particular building unit. Then, in order to find the most stable 
location of the $\mathrm{Et}_{6} \mathrm{DQ}_{5}$ cation, we performed molecular mechanics simulations, as implemented in Forcite module in Materials Studio software [30]. The geometry of the ferrierite structure was kept fixed during these calculations. Molecular structures and the interaction energies of the organic SDAs with the framework were described with the Dreiding forcefield [31]. In molecular mechanics calculations, supercells composed of 1x1x4 FER unit cells were used in order to prevent artificial restrictions imposed by periodicity; in these models, two $\mathrm{Et}_{6} \mathrm{DQ}_{5}$ dications along each $10 \mathrm{MR}$ channel were loaded in order to study packing interactions between consecutive $\mathrm{Et}_{6} \mathrm{DQ}_{5}$ cations. The cations were manually docked in the framework in different orientations, and the most stable location was obtained by simulated annealing.

Once we unraveled the location of the flexible organic cation, our next challenge was to understand the particular features observed in the ${ }^{13} \mathrm{C}$ NMR spectra of the FER material compared with that of the $\mathrm{Et}_{6} \mathrm{DQ}_{5}$ cation in aqueous solution. For this study, we performed geometry-optimization calculations with $\mathrm{DFT}+\mathrm{D}$ methods, followed by theoretical calculation of the ${ }^{13} \mathrm{C}$ NMR chemical shifts. These calculations were performed with the CASTEP code [32] using plane waves (with an energy cut off of 571.4 $\mathrm{eV}$ ), and the PBE functional (including the Grimme dispersion term) [33]. Calculation of the ${ }^{13} \mathrm{C}$ NMR chemical shieldings was carried out with the gauge-including projector augmented-wave method (GIPAW) developed by Pickard and Mauri [34], as implemented in the CASTEP code. The chemical shift for a nucleus in a given position $(\delta(\mathrm{r}))$ is defined as: $\delta(\mathrm{r})=\sigma_{\mathrm{ref}}-\sigma(\mathrm{r})$, where $\sigma(\mathrm{r})$ is the isotropic shielding obtained in the calculations. In order to compare with experimental ${ }^{13} \mathrm{C}$ chemical shifts, a $\sigma_{\text {ref }}$ value of $174 \mathrm{ppm}$ (the same as in our previous works $[16,28]$ ) was used. 
In these DFT calculations, we had to use smaller models of the FER zeolite. For this reason, in order to study the effect of the confinement of the three ethyl groups attached to each quaternary $\mathrm{N}$ atom of $\mathrm{Et}_{6} \mathrm{DQ}_{5}$, we used triethylmethylammonium (TEMA) cations hosted in single FER unit cells as a model. This allowed us to study the ${ }^{13} \mathrm{C}$ NMR chemical shifts of the ethyl groups as a function of their location in the FER microporous structure. On the other hand, in order to understand the flexibility of the $\mathrm{Et}_{6} \mathrm{DQ}_{5}$ dication upon confinement and the effect on the ${ }^{13} \mathrm{C}$ NMR chemical shifts, we calculated the stability and theoretical isotropic ${ }^{13} \mathrm{C}$ shieldings of different conformations of the $\mathrm{Et}_{6} \mathrm{DQ}_{5}$ dication in vacuum, following our previous observations by molecular mechanics, and compared with the experimental NMR results.

\section{RESULTS AND DISCUSSION}

\subsection{Synthesis results}

Table 1 shows the crystalline phases obtained from the different synthetic experiments performed, both when $\mathrm{Et}_{6} \mathrm{DQ}_{5}$ was used alone or together with co-SDAs. In the absence of co-SDAs, Et $6 \mathrm{DQ}_{5}$ led to the crystallization of zeolite beta (BEA), together with another phase that has not been identified, with the usual $\mathrm{Et}_{6} \mathrm{DQ}_{5}(\mathrm{OH})_{2} / \mathrm{T}$ ratio of 0.54 (Figure 1, top-left). When the $\mathrm{Et}_{6} \mathrm{DQ}_{5}(\mathrm{OH})_{2} / \mathrm{T}$ ratio was decreased to 0.27 , keeping a Si/Al ratio of 15 , beta zeolite was obtained as pure phase, although with a poor crystallinity.

We then used small organic species together with $\mathrm{Et}_{6} \mathrm{DQ}_{5}$ in an attempt to promote the crystallization of more complex materials. When pyrrole (sample $0.27 \mathrm{Et}_{6} \mathrm{DQ}_{5}$ 0.27pyrrol/15) and tert-butylamine (sample $0.27 \mathrm{Et}_{6} \mathrm{DQ}_{5}-0.27$ tertbutyl/15) were used together with $\mathrm{Et}_{6} \mathrm{DQ}_{5}(\mathrm{OH})_{2}$, beta-like zeolites were obtained (Figure 1, bottom-left). 
These results show that theses amines are not playing a major role in the crystallization process.

Following our previous studies [21,24], TMA was then used as co-SDA. When we used a high amount of TMA (TMA/T $=0.27$, sample $\left.0.27 \mathrm{Et}_{6} \mathrm{DQ}_{5}-0.27 \mathrm{tma} / 15\right)$, a mixture of phases containing zeolites SOD, RUT and OFF was obtained (Figure 1-right, (a)). These frameworks are known to crystallize in the presence of TMA [35-37], where TMA cations stabilize the corresponding cage-like building units (sod, rut and gme) because of an adequate host-guest fit. Lowering the $\mathrm{pH}$ (to 9.13) under otherwise similar conditions led to the crystallization of ferrierite and sodalite structures (sample $0.27 \mathrm{Et}_{6} \mathrm{DQ}_{5}-0.27 \mathrm{tma} / 15$ EHF, Figure 1-right, (b)). In an attempt to eliminate the sodalite phase, the amount of TMA was decreased to TMA/T $=0.135$, but instead another phase that has not yet been identified emerged (sample 0.405Et $6 \mathrm{DQ}_{5}-0.135 \mathrm{tma} / 15$, (c), denoted as $\mathrm{X}$ ).

When the amount of $\mathrm{Al}$ was increased $(\mathrm{Si} / \mathrm{Al}=10)$, keeping the stoichiometric amount of $\mathrm{HF}(\mathrm{pH}=11.73)$, sodalite zeolite was obtained as pure phase (sample $0.27 \mathrm{Et}_{6} \mathrm{DQ}_{5}$ $0.27 \mathrm{tma} / 10,(\mathrm{~d}))$. However, when the $\mathrm{pH}$ of the gel was lowered to 9.38 by the addition of excess HF, pure and crystalline ferrierite zeolite was obtained (sample 0.27Et6 $\mathrm{DQ}_{5}$ 0.27tma/10 EHF, (e); see Figure S2 in the Supporting Information). Further addition of $\mathrm{Al}$ to the gel $(\mathrm{Si} / \mathrm{Al}=8)$ while keeping the stoichiometric amount of $\mathrm{HF}(\mathrm{pH}=11.10)$ resulted in the crystallization of ferrierite together with a minor amount of sodalite (sample $0.27 \mathrm{Et}_{6} \mathrm{DQ}_{5}-0.275 \mathrm{tma} / 8$, (f)). Again lowering the $\mathrm{pH}$ of the gel synthesis to 8.93 drove the crystallization to pure ferrierite zeolite (sample $0.27 \mathrm{Et}_{6} \mathrm{DQ}_{5}-0.275 \mathrm{tma} / 8 \mathrm{EHF}$, (g)). In contrast, higher $\mathrm{Si} / \mathrm{Al}$ ratios of 23 and 15 did not result in pure ferrierite. This result is in contrast to our previous observation with a bis-methylpyrrolidinium-based flexible dication [24], where ferrierite was obtained with $\mathrm{Si} / \mathrm{Al}$ ratios of 23 and 15, what 
suggests that the crystallization of ferrierite with $\mathrm{Et}_{6} \mathrm{DQ}_{5}$ requires a higher amount of $\mathrm{Al}$. As observed in our previous works, the co-structure-directing role of TMA for the crystallization of FER materials is crucial because this small cation directs the crystallization of the small fer cavities.

\subsection{Characterization of TMA-Et $6 \mathrm{DQ}_{5}$-ferrierite}

We then characterized the pure ferrierite samples obtained. Field-Emission SEM pictures of the materials (Figure 2) revealed a high crystallinity, where ferrierite crystallizes as interpenetrated plates in a rather unusual morphology for this zeolite.

The ${ }^{29}$ Si MAS NMR spectra (Figure S3 in the Supporting Information) show a wide resonance in the range of -100 to $-120 \mathrm{ppm}$ with a maximum at $-112.5 \mathrm{ppm}$, which is indicative of the existence of multiple $\mathrm{T}$ sites in the structure. The incorporation of $\mathrm{Al}$ into the zeolitic network in tetrahedral coordination was confirmed by ${ }^{27} \mathrm{Al}$ MAS NMR (Figure S4 in the Supporting Information). The spectra of the samples consist of a single, narrow signal at $49.4 \mathrm{ppm}$, assigned to $\mathrm{Al}$ in tetrahedral coordination in the zeolitic network. The absence of signals at $0 \mathrm{ppm}$ indicates that there is no extra-framework octahedral Al. The Si/Al molar ratio of the samples, as determined by ICP-AES, was 8.28.6, as shown in Table 2, which is not far from the nominal ratio in the gel. These values correspond to an $\mathrm{Al}$ content of 3.7 and 3.9 atoms per FER unit cell for the samples obtained with $\mathrm{Si} / \mathrm{Al}$ ratios in the gel of 10 and 8 , respectively. ${ }^{19} \mathrm{~F}$ NMR (Figure S5 in the Supporting Information) indicates that there is no zeolitic fluoride occluded in the ferrierite materials (which should give a band at around -60 ppm [38]) since only signals with a very low intensity at $-123,-176$ and $-191 \mathrm{ppm}$ are observed; these signals must be associated to $\mathrm{F}$ bonded to penta or hexacoordinated $\mathrm{Si}$ (or $\mathrm{Al}$ ) in the outer surface of the 
crystals. Therefore, F does not seem to play any structural role in the ferrierite framework obtained here. This might suggest that the beneficial effect of adding extra HF for crystallizing pure ferrierite is associated to a lower $\mathrm{pH}$, rather to a higher amount of $\mathrm{F}$. However, the role of $\mathrm{F}$ as mineralizing agent is crucial during the crystallization of these ferrierite materials.

The organic content of the ferrierite samples, as determined by thermogravimetric and $\mathrm{CHN}$ chemical analysis, is reported in Table 2. The $\mathrm{C} / \mathrm{N}$ ratio of the samples was 5.5-5.6, which is between the ratio of the two cations $\left(\mathrm{Et}_{6} \mathrm{DQ}_{5}, \mathrm{C} / \mathrm{N}=8.5\right.$, and TMA, $\left.\mathrm{C} / \mathrm{N}=4\right)$, suggesting that both are occluded within the structure. This relationship is closer to TMA than to $\mathrm{Et}_{6} \mathrm{DQ}_{5}$, suggesting that the $\mathrm{TMA} / \mathrm{ET}_{6} \mathrm{DQ}_{5}$ ratio is higher than 1 ; the total amount of $\mathrm{N}$ atoms per unit cell was 3.7-3.8. Indeed, despite the different $\mathrm{Al}$ contents used in the gel, ICP and CHN chemical analyses show that the $\mathrm{N}$ and $\mathrm{Al}$ contents are similar in both samples (see Table 2), and are close to the $\mathrm{N}$ content for charge-balance reasons. These results confirm that the amount of $\mathrm{Al}$ in the final ferrierite material is determined by the amount of positive charges (in the form of quaternary $\mathrm{N}$ atoms) able to be accommodated within the ferrierite framework, as observed in our previous work [24].

The integrity of $\mathrm{Et}_{6} \mathrm{DQ}_{5}$ and TMA cations within the ferrierite structure was evaluated by ${ }^{13} \mathrm{C}$ CP MAS NMR (Figure 3); the ${ }^{13} \mathrm{C}$ NMR spectrum of an aqueous solution of the $\mathrm{Et}_{6} \mathrm{DQ}_{5}$ dication is also shown for comparison purposes. In the aqueous solution of the dication, signals at $6.6,20.8,22.8,52.7$ and $56.0 \mathrm{ppm}$ are assigned, according to their chemical shift and relative ratio, to $\mathrm{C}$ atoms of $\mathrm{Et}_{6} \mathrm{DQ}_{5}$ labelled as $\mathrm{C} 5, \mathrm{C} 2, \mathrm{C} 1, \mathrm{C} 4$ and C3, respectively (see Figure 3-inlet). Interestingly, when this dication is confined within the ferrierite framework, several alterations of the ${ }^{13} \mathrm{C}$ NMR bands are featured. Firstly, the signal corresponding to $\mathrm{C} 5$ splits in two bands at 5.6 and $8.8 \mathrm{ppm}$, the latter with a 
higher intensity. Something similar occurs for the $\mathrm{C} 4$ band, which splits in two bands at 52.1 and $53.3 \mathrm{ppm}$, the latter with a higher intensity. These bands are associated to the ethyl substituents, and suggest a different environment for the ethyl groups of $\mathrm{Et}_{6} \mathrm{DQ}_{5}$ in the ferrierite framework. Moreover, taking into account the intensity of the bands corresponding to $\mathrm{C} 1$ and $\mathrm{C} 2$ (there are two $\mathrm{C} 2$ and one $\mathrm{C} 1$ atoms in $\mathrm{Et}_{6} \mathrm{DQ}_{5}$ ), we observe that these are shifted with respect to the dication in aqueous solution, giving a signal with a higher intensity at $22.9 \mathrm{ppm}$ and another signal with a lower intensity at $20.2 \mathrm{ppm}$. These NMR alterations are a direct consequence of the confinement of $\mathrm{Et}_{6} \mathrm{DQ}_{5}$ in the ferrierite framework. On the other hand, the presence of TMA is evidenced by the band at $57.7 \mathrm{ppm}$ with a high intensity, which is typical of methyl TMA groups confined within the fer cavities [21,23]. Therefore, these results indicate that both cations are occluded intact within the ferrierite framework, although the spectrum of the $\mathrm{Et}_{6} \mathrm{DQ}_{5}$ dication is notably altered upon confinement.

\subsection{Computational results}

Molecular mechanics simulations: host-guest fit of FER $\cdots E t_{6} D Q_{5}$

We next tried to understand the structure-directing effect of the $\mathrm{Et}_{6} \mathrm{DQ}_{5}$ dication during the crystallization of the FER framework. First of all, we performed molecular mechanics simulations in order to find the most stable arrangement of $\mathrm{Et}_{6} \mathrm{DQ}_{5}$ cations within the FER channels; we know from previous studies that TMA locates within the fer cavities [21,23]. In order to optimize the packing between consecutive $\mathrm{Et}_{6} \mathrm{DQ}_{5}$ dications, models consisting of $1 \times 1 \times 4$ FER supercells with $2 \mathrm{Et}_{6} \mathrm{DQ}_{5}$ dications along the $10 \mathrm{MR}$ channels were built, and the most stable arrangement was obtained by simulated annealing protocols. After a preliminary set of calculations, we found two possible relative 
orientations between adjacent $\mathrm{Et}_{6} \mathrm{DQ}_{5}$ dications, with 0 or $180^{\circ}$ rotations around the ' $\mathrm{c}$ ' axis (see Figure 4, 'A' vs ' $\mathrm{B}$ ' or 'C' vs ' $\mathrm{D}$ '). Our calculations showed that the $\mathrm{Et}_{6} \mathrm{DQ}_{5}$ dications locate with the bulky triethylammonium groups in the intersections between the $10 \mathrm{MR}$ and $8 \mathrm{MR}$ channels, siting two of the ethyl arms aligned with the 8MR channel and the other ethyl group aligned with the 10MR channel (Figure 5). After relaxing the position of the dications, we found two different stable configurations for the $\mathrm{Et}_{6} \mathrm{DQ}_{5}$ dications, one where the pentyl chain is stretched, with the four torsion angles of the alkyl spacer around $180^{\circ}$ in anti configuration (Figure 6-A), and another where the alkyl chain is squeezed, with two of the $\mathrm{C}-\mathrm{C}$ bonds in anti configuration and the other two in gauge configuration (Figure 6-B). Relative energies for the two $\mathrm{Et}_{6} \mathrm{DQ}_{5}$ conformations ('stretched' and 'squeezed') and the two orientations between adjacent $\mathrm{Et}_{6} \mathrm{DQ}_{5}$ cations (' 0 ' ' and ' $180^{\circ}$ ' around c) are displayed in Table 3. Of all the possible arrangements, the one with $\mathrm{Et}_{6} \mathrm{DQ}_{5}$ dications in 'stretched' conformation and ' 0 ' ' orientation was very unstable, probably because of strong repulsive interactions between adjacent ethyl groups along the 10MR channel (Figure 4-A). Such repulsive interactions are partially avoided if adjacent cations are consecutively rotated by $180^{\circ}$, giving a more stable packing arrangement (Figure 4-B). The most stable arrangements involve a squeeze of the pentyl chain of the $\mathrm{Et}_{6} \mathrm{DQ}_{5}$ dications, where two of the $\mathrm{C}-\mathrm{C}$ bonds change from anti to gauge conformation. Figure 6 displays a detailed picture of the two $\mathrm{Et}_{6} \mathrm{DQ}_{5}$ conformations available in FER ('A' for 'stretched' and 'B' for 'squeezed'). Such change of conformation involves a slight reduction of the separation between the $\mathrm{N}$ atoms from $\sim 7.9$ (in the 'stretched' conformation) to $\sim 7.4 \AA$ (in the 'squeezed' conformation) (Figure 6). This allows a best fit with the 'c' parameter of the FER framework of $\sim 7.5 \AA$, and hence a best accommodation of the $\mathrm{Et}_{6} \mathrm{DQ}_{5}$ dication with each bulky ammonium group in 
consecutive channel intersections (Figure 5-bottom). Again, a higher stability is found when consecutive 'squeezed' $\mathrm{Et}_{6} \mathrm{DQ}_{5}$ dications rotate $180^{\circ}$ consecutively (Table 3 ) since, in this case, repulsive interactions between adjacent cations are avoided (Figure 4-D). DFT calculations: Theoretical ${ }^{13} C N M R$ of $E t_{6} D Q_{5}$

Once we found the most stable arrangement of the $\mathrm{Et}_{6} \mathrm{DQ}_{5}$ dications in the FER framework, we tried to understand the particular features of the ${ }^{13} \mathrm{C}$ NMR spectra of the dication that, as previously mentioned, displayed two singular features upon confinement: a splitting of the ${ }^{13} \mathrm{C}$ signals assigned to methyl (C5) and methylene (C4) groups of the ethyl substituents, and the shift of the bands assigned to $\mathrm{C} 1$ and $\mathrm{C} 2$ atoms in the alkyl spacer.

We first studied the splitting of the C4 and C5 signals. Due to the limited size of the FER model required to perform NMR theoretical calculations by DFT methods, for this study we used FER single cells loaded with triethylmethylammonium (TEMA) cations as a model for the triethylammonium groups of $\mathrm{Et}_{6} \mathrm{DQ}_{5}$. TEMA cations were loaded in an equivalent position as that of $\mathrm{Et}_{6} \mathrm{DQ}_{5}$; then the FER-TEMA systems were geometryoptimized, and the theoretical ${ }^{13} \mathrm{C}$ NMR chemical shifts were calculated. Results are reported in Table 4 and Figure 7. Interestingly, we observe two different bands for C5 atoms of the ethyl groups depending on their location: the two ethyl groups located aligned with the $8 \mathrm{MR}$ channels display ${ }^{13} \mathrm{C}$ NMR shifts at $9.4 \mathrm{ppm}$, while the other ethyl group which is aligned with the $10 \mathrm{MR}$ channel shifts upfield to $7.7 \mathrm{ppm}$. This is in very good agreement with the experimental observations where a band with a higher intensity was observed at $8.8 \mathrm{ppm}$, and another with a lower intensity at $5.6 \mathrm{ppm}$, and are accordingly assigned to $\mathrm{C} 5$ of $\mathrm{Et}_{6} \mathrm{DQ}_{5}$ in $8 \mathrm{MR}$ and $10 \mathrm{MR}$ channels, respectively, the former undergoing a stronger confinement since C5 atoms are in the middle of the smaller 
8-ring windows (Figure 7). Something similar was observed for the theoretical shift of $\mathrm{C} 4$, where two bands at 64.4 and $54.0 \mathrm{ppm}$ were predicted for $\mathrm{C} 4$ in $8 \mathrm{MR}$ and $10 \mathrm{MR}$ channels, respectively, again in good agreement with the two bands observed at 53.3 and $52.1 \mathrm{ppm}$, the former with higher intensity. In this case the experimental split was smaller, possibly due to the use of TEMA as a model for $\mathrm{Et}_{6} \mathrm{DQ}_{5}$, where the alkyl chain is replaced by a methyl group. Hence, this set of results suggested that the splitting of the C5 and C4 bands of $\mathrm{Et}_{6} \mathrm{DQ}_{5}$ dication upon confinement in the FER framework is a consequence of the two different environments of the ethyl arms sited in the 8MR or 10MR channels. We then tried to analyze the alterations of the chemical shifts of $\mathrm{C} 1$ and $\mathrm{C} 2$ of $^{\mathrm{Et}} \mathrm{t}_{6} \mathrm{DQ}_{5}$ dications hosted in the FER framework. Our previous molecular-mechanics results had suggested that conformational changes occurring upon confinement might cause the observed alterations of the ${ }^{13} \mathrm{C}$ NMR spectrum. In this case, due to the large FER cell required to properly model the packing interactions between adjacent $\mathrm{Et}_{6} \mathrm{DQ}_{5}$ dications (1x1x4 FER u.c.), we decided to study the ${ }^{13} \mathrm{C}$ NMR isotropic shieldings of the dication in vacuum as a function of the conformation adopted. Apart from the two conformations previously mentioned (Figure 6, 'A' and 'B'), obtained from the confinement of the dication in the FER 10MR channels in the two configurations of the alkyl spacer ('stretched' and 'squeezed'), we also obtained by simulated annealing the most stable conformation of $\mathrm{Et}_{6} \mathrm{DQ}_{5}$ in vacuum, which was in a similar 'stretched' configuration of the alkyl spacer but with a distinct orientation of the ethyl groups ('stretched-vac' in Figure 6-C). We then calculated the theoretical ${ }^{13} \mathrm{C}$ NMR chemical shifts for the three conformations (Table 5). Energy results show that the relative order of conformational stability in vacuum, as determined by Dreiding or DFT methods, is similar: as expected, conformations in 'stretched' configuration of the alkyl chain are rather more stable (by 
more than $5 \mathrm{kcal} / \mathrm{mol})$. We now look at the theoretical ${ }^{13} \mathrm{C}$ chemical shifts of the most stable conformation, 'stretched-vac' (' $\mathrm{C}$ ' in Figure 6). All the methyl $\mathrm{C} 5$ atoms give a resonance around 5 ppm, while $\mathrm{C} 4$ atoms give a resonance around $57 \mathrm{ppm}$; both signals assigned to the six ethyl groups are in very good agreement with the experimental observations of the aqueous solution of the $\mathrm{Et}_{6} \mathrm{DQ}_{5}$ dication. $\mathrm{C} 1$ and $\mathrm{C} 2$ atoms of the alkyl chain give theoretical ${ }^{13} \mathrm{C}$ shifts at around 27 and 24 , respectively, the latter more intense because of the higher proportion $(2 \mathrm{C} 2: 1 \mathrm{C} 1)$, while $\mathrm{C} 3$ gives a theoretical shift at 59 ppm. These calculated ${ }^{13} \mathrm{C}$ chemical shifts of the alkyl chain are again in very good agreement with the experimental ${ }^{13} \mathrm{C}$ NMR spectrum of the dication in aqueous solution, and hence we conclude that this 'stretched-vac' conformation is the one adopted by the dication in aqueous solution. This is in line with the higher stability of this conformer, as determined by Dreiding and DFT calculations.

If we compare the theoretical ${ }^{13} \mathrm{C}$ NMR chemical shifts with that of the 'stretched-FER' conformation, where the alkyl chain is also in the same anti configuration and only the orientation of the ethyl groups is slightly modified, we observe that the shifts are very similar to the 'stretched-vac' conformation, with only $\mathrm{C} 3$ and $\mathrm{C} 4$ atoms being slightly downfield shifted. However, the relative position of $\mathrm{C} 1$ and $\mathrm{C} 2$ chemical shifts is the same, suggesting that this conformation is not the one adopted by the dication in the actual ferrierite material.

We finally calculated the theoretical ${ }^{13} \mathrm{C}$ NMR shifts for the dication in the 'squeezedFER' conformation (Figure 6-B), which was the most stable arrangement found previously for $\mathrm{Et}_{6} \mathrm{DQ}_{5}$ dications confined within the FER framework. Again we observe that C5 and C4 theoretical shifts are similar to those in the 'stretched' configuration, around 5 and $57 \mathrm{ppm}$, respectively. Interestingly, the change of conformation from the 
'stretched' to the 'squeezed' configuration, where two of the anti C-C configurations become gauge, involves a split of the $\mathrm{C} 2$ atoms, shifting from $23.6 \mathrm{ppm}$ (in the 'stretchedvac' conformer) to 21.3 and $26.6 \mathrm{ppm}$, respectively, while C3 resonates at $28.6 \mathrm{ppm}$. The notable downfield shift of $\mathrm{C} 2$ to $26.6 \mathrm{ppm}$ is caused by the arrangement in gauge configuration with the $\mathrm{N}$ ammonium group, withdrawing electron density and hence triggering a ${ }^{13} \mathrm{C}$ deshielding. Overall, this means that this 'squeezed' conformation should give two bands between 26.6-28.6 ppm (corresponding to $\mathrm{C} 1$ and one of the $\mathrm{C} 2$ atoms), and one band around $21 \mathrm{ppm}$ (corresponding to the other C2). If we compare now with the experimental ${ }^{13} \mathrm{C}$ NMR spectrum of the ferrierite material, we observe that this is in very good agreement with the observed bands assigned to C1 and C2 (Figure 3).

Therefore, we conclude that the particular features of the ${ }^{13} \mathrm{C}$ NMR spectrum of our ferrierite material are due, on the one hand, to different locations of the ethyl groups resulting in distinct confinement effects (splitting of $\mathrm{C} 4$ and $\mathrm{C} 5$ bands), and on the other, to a change of conformation of the flexible $\mathrm{Et}_{6} \mathrm{DQ}_{5}$ dications that are squeezed in a sort of "accordion"-like effect in order to adjust their dimension with that of the ferrierite framework, allowing to host their bulky ammonium groups in the intersections with the 8MR channels. Such an "accordion"-like effect is inherent to the high flexibility of this type of dications with long alkyl spacers, providing an advantage to this type of SDA species since they can adjust their dimensions to those of different zeolite frameworks by stretching or squeezing their flexible spacers through rotations of the $\mathrm{C}-\mathrm{C}$ bonds. This effect also explains, for instance, that 1,2-dimethylimidazolium dications with alkyl spacers of 4,5 and 6 methylene units can drive the crystallization of the same STW framework, resulting in alterations of the ${ }^{13} \mathrm{C}$ NMR spectra because of conformational changes, as observed in previous works [16]. 


\section{CONCLUSIONS}

In this work we have studied the structure-directing effect of a highly flexible dication ( $N, N^{\prime}$-bis-triethylpentanediyldiammonium) combined with a small co-structure-directing agent, tetramethylammonium, towards the crystallization of zeolite materials. Under certain conditions, specifically low $\mathrm{pH}$ and moderately high $\mathrm{Al}$ content, the combination of these two dications enabled the crystallization of pure ferrierite materials, where both cations were occluded within the framework. ${ }^{13} \mathrm{C}$ NMR results showed particular features of the bands corresponding to the flexible dication confined within the ferrierite framework. A combination of molecular mechanics and DFT calculations allowed us to understand such particular NMR results. On the one hand, splitting of the bands associated to the $\mathrm{C}$ atoms of the ethyl groups occurs because two of the six ethyl groups locate aligned with the 10MR channels, while the other four ethyl groups site aligned with the $8 \mathrm{MR}$ channels, thus providing different environments and consequently different ${ }^{13} \mathrm{C}$ resonances. On the other hand, the high flexibility of the alkyl spacer of the dications and the fixed separation between consecutive channel intersections in FER involves that the alkyl spacer is squeezed upon confinement in the 10MR channels in order to adapt its dimension along the channel direction to that of FER, thus enabling to locate both bulky quaternary ammonium groups in the channel intersections, aligned with the $8 \mathrm{MR}$ channels. Such alteration of the molecular conformation involves a shift of the ${ }^{13} \mathrm{C}$ resonances of the atoms involved, which explains the experimental ${ }^{13} \mathrm{C} N M R$ results. Hence, we propose a new effect during structure-direction associated to highly flexible dications that we have designated as an "accordion"-like effect, where organic dications 
adapt their dimensions to those of the zeolite framework they direct through the conformational space provided by their flexible alkyl spacer units.

\section{ACKNOWLEDGEMENTS}

This work has been partially financed by the Spanish State Research Agency (Agencia Española de Investigación, AEI) and the European Regional Development Fund (Fondo Europeo de Desarrollo Regional, FEDER) through the Project MAT2016-77496-R (AEI/FEDER, UE), and by Consejo Superior de Investigaciones Científicas (CSIC) through project 201780I043. R.K.S.A. is grateful to Fundação de Amparo à Pesquisa do Estado de São Paulo - FAPESP (Process no 2014/10609-5) for the scholarship and financial support during post-doctoral internship at Instituto de Catálisis y Petroleoquímica (CSIC). Secretaría General Adjunta de Informática-CSIC is acknowledged for running the calculations, and BIOVIA for providing the computational software. 


\section{Tables}

Table 1. Summary of the synthesis experiments performed (crystallization at $160{ }^{\circ} \mathrm{C}$ for 14 days), and crystalline products obtained.

\begin{tabular}{llllll}
\hline Sample & SDAs & Si/Al gel & HF/(Si+Al $)$ & pH $_{\text {gel }}$ & Phase \\
\hline $0.54 \mathrm{Et}_{6} \mathrm{DQ}_{5} / 15$ & $\mathrm{Et}_{6} \mathrm{DQ}_{5}$ & 15 & $\mathbf{1 . 0 9}$ & 11.2 & $\mathrm{BEA}+\mathrm{UP}^{\mathrm{a}}$ \\
$0.54 \mathrm{Et}_{6} \mathrm{DQ}_{5} / 10$ & $\mathrm{Et}_{6} \mathrm{DQ}_{5}$ & 10 & $\mathbf{1 . 0 9}$ & 11.4 & $\mathrm{BEA}+\mathrm{UP}^{\mathrm{a}}$ \\
$0.54 \mathrm{Et}_{6} \mathrm{DQ}_{5} / 8$ & $\mathrm{Et}_{6} \mathrm{DQ}_{5}$ & 8 & $\mathbf{1 . 0 9}$ & 10.7 & $\mathrm{BEA}+\mathrm{UP}^{\mathrm{a}}$ \\
$0.27 \mathrm{Et}_{6} \mathrm{DQ}_{5}-0.27 \mathrm{pyrrol} / 15$ & $\mathrm{Et}_{6} \mathrm{DQ}_{5}+\mathrm{PYRROL}$ & 15 & $\mathbf{0 . 5 1}$ & 11.8 & $\mathrm{BEA}$ \\
$0.27 \mathrm{Et}_{6} \mathrm{DQ}_{5}-0.27 \mathrm{tertbutyl} / 15$ & $\mathrm{Et}_{6} \mathrm{DQ}_{5}+t \mathrm{BuA}$ & 15 & $\mathbf{0 . 5 1}$ & 10.6 & $\mathrm{BEA}$ \\
$0.27 \mathrm{Et}_{6} \mathrm{DQ}_{5}-0.27 \mathrm{tma} / 15$ & $\mathrm{Et}_{6} \mathrm{DQ}_{5}+\mathrm{TMA}$ & 15 & $\mathbf{0 . 8 0}$ & 12.1 & $\mathrm{SOD}+\mathrm{RUT}+\mathrm{OFF}$ \\
$0.27 \mathrm{Et}_{6} \mathrm{DQ}_{5}-0.27 \mathrm{tma} / 15 \mathrm{EHF}$ & $\mathrm{Et}_{6} \mathrm{DQ}_{5}+\mathrm{TMA}$ & 15 & $\mathbf{1 . 3 5}$ & 9.1 & $\mathrm{FER}+\mathrm{SOD}$ \\
$0.405 \mathrm{Et}_{6} \mathrm{DQ}_{5}-0.135 \mathrm{tma} / 15$ & $\mathrm{Et}_{6} \mathrm{DQ}_{5}+\mathrm{TMA}$ & 15 & $\mathbf{0 . 9 4}$ & 11.6 & $\mathrm{FER}+\mathrm{SOD}+\mathrm{X}^{\mathrm{b}}$ \\
$0.27 \mathrm{Et}_{6} \mathrm{DQ}_{5}-0.27 \mathrm{tma} / 10$ & $\mathrm{Et}_{6} \mathrm{DQ}_{5}+\mathrm{TMA}$ & 10 & $\mathbf{0 . 8 0}$ & 11.7 & $\mathrm{SOD}$ \\
$0.27 \mathrm{Et}_{6} \mathrm{DQ}_{5}-0.27 \mathrm{tma} / 10 \mathrm{EHF}$ & $\mathrm{Et}_{6} \mathrm{DQ}_{5}+\mathrm{TMA}$ & 10 & $\mathbf{1 . 3 4}$ & 9.4 & $\mathrm{FER}$ \\
$0.27 \mathrm{Et}_{6} \mathrm{DQ}_{5}-0.27 \mathrm{tma} / 8$ & $\mathrm{Et}_{6} \mathrm{DQ}_{5}+\mathrm{TMA}$ & 8 & $\mathbf{0 . 8 0}$ & 11.1 & FER + SOD \\
$0.27 \mathrm{Et}_{6} \mathrm{DQ}_{5}-0.27 \mathrm{tma} / 8 \mathrm{EHF}$ & $\mathrm{Et}_{6} \mathrm{DQ}_{5}+\mathrm{TMA}$ & 8 & $\mathbf{1 . 6 0}$ & 8.9 & $\mathrm{FER}$ \\
\hline
\end{tabular}

${ }^{\mathrm{a}}$ Undefined phase; ${ }^{\mathrm{b}}$ Another undefined phase

Table 2. CHN, TGA and ICP chemical analyses of the ferrierite samples obtained.

\begin{tabular}{|c|c|c|c|c|c|c|c|c|c|}
\hline \multirow{2}{*}{ Samples } & \multicolumn{4}{|c|}{ Chemical Analysis (wt\%) } & \multirow{2}{*}{$\begin{array}{l}\text { TGA } \\
\text { Organic (wt\%) }\end{array}$} & \multirow{2}{*}{ N/u.c. } & \multicolumn{2}{|l|}{ ICP } & \multirow{2}{*}{ Product } \\
\hline & $\mathbf{C}$ & $\mathbf{H}$ & $\mathbf{N}$ & $\mathbf{C} / \mathbf{N}$ & & & $\mathbf{S i} / \mathbf{A l}$ & Al/u.c. & \\
\hline $0.27 \mathrm{Et}_{6} \mathrm{DQ}_{5}-0.27 \mathrm{tma} / 10 \mathrm{EHF}$ & 9.40 & 2.31 & 2.00 & 5.50 & 15.0 & 3.65 & 8.61 & 3.75 & FER \\
\hline $0.27 \mathrm{Et}_{6} \mathrm{DQ}_{5}-0.27 \mathrm{tma} / 8 \mathrm{EHF}$ & 10.01 & 2.37 & 2.07 & 5.64 & 16.0 & 3.83 & 8.19 & 3.91 & FER \\
\hline
\end{tabular}


Table 3. Relative stability (given as the relative energy per $\mathrm{Et}_{6} \mathrm{DQ}_{5}$ dication with respect to the most stable case, 'squeezed-180', expressed in kcal/mol units) of the different FER$\mathrm{Et}_{6} \mathrm{DQ}_{5}$ systems studied by molecular mechanics calculations.

\begin{tabular}{|c|c|c|}
\hline Et$_{6} \mathbf{D Q}_{5}$ conformation & Et $_{6} \mathbf{D Q}_{5}$ orientation & Relative Energy \\
\hline Stretched & $0^{\circ}$ & +21.1 \\
\hline Stretched & $180^{\circ}$ & +2.5 \\
\hline Squeezed & $0^{\circ}$ & +0.4 \\
\hline Squeezed & $180^{\circ}$ & 0.0 \\
\hline
\end{tabular}

Table 4. Theoretical ${ }^{13} \mathrm{C}$ NMR chemical shifts of triethylmethylammonium (TEMA) cations in the FER framework as a function of the ethyl group location.

\begin{tabular}{|c|c|c|}
\hline C Atom & Location & Theor. ${ }^{\mathbf{1 3}} \mathbf{C} \boldsymbol{\delta}$ \\
\hline \multirow{3}{*}{ C5 } & $8 \mathrm{MR}$ & 9.4 \\
\cline { 2 - 3 } & $8 \mathrm{MR}$ & 9.4 \\
\cline { 2 - 3 } & $10 \mathrm{MR}$ & 7.7 \\
\hline \multirow{3}{*}{4} & $8 \mathrm{MR}$ & 64.4 \\
\cline { 2 - 3 } & $8 \mathrm{MR}$ & 64.4 \\
\cline { 2 - 3 } & $10 \mathrm{MR}$ & 54.0 \\
\hline
\end{tabular}


Table 5. Theoretical ${ }^{13} \mathrm{C}$ NMR chemical shifts of $\mathrm{Et}_{6} \mathrm{DQ}_{5}$ dications in vacuum as a function of the conformation. Relative energies $(\Delta \mathrm{E})$ are given in $\mathrm{kcal} / \mathrm{mol}$, as calculated by DFT or Dreiding methods.

\begin{tabular}{|c|c|c|c|c|c|c|c|}
\hline Conformation & $\Delta \mathrm{E}(\mathrm{DFT})$ & $\Delta \mathrm{E}($ Dreid $)$ & $\mathrm{C5}$ & $\mathrm{C2}$ & C1 & C4 & $\mathrm{C3}$ \\
\hline \multirow{6}{*}{$\begin{array}{c}\text { Stretched-FER } \\
\text { (A in Fig. 5) }\end{array}$} & \multirow[t]{6}{*}{1.9} & \multirow[t]{6}{*}{0.4} & 5.2 & 24.2 & 27.1 & 59.9 & 62.5 \\
\hline & & & 5.1 & 24.1 & & 60.2 & 62.4 \\
\hline & & & 5.4 & & & 61.1 & \\
\hline & & & 5.2 & & & 59.8 & \\
\hline & & & 5.0 & & & 59.9 & \\
\hline & & & 5.4 & & & 61.0 & \\
\hline \multirow{6}{*}{$\begin{array}{l}\text { Stretched-vac } \\
\text { (C in Fig. 5) }\end{array}$} & \multirow[t]{6}{*}{0.0} & \multirow[t]{6}{*}{0.0} & 4.7 & 23.6 & 27.1 & 57.4 & 59.2 \\
\hline & & & 4.4 & 23.6 & & 57.5 & 59.1 \\
\hline & & & 4.8 & & & 57.3 & \\
\hline & & & 4.7 & & & 57.4 & \\
\hline & & & 4.6 & & & 57.4 & \\
\hline & & & 4.4 & & & 57.4 & \\
\hline \multirow{6}{*}{$\begin{array}{l}\text { Squeezed-FER } \\
\text { (B in Fig. 5) }\end{array}$} & \multirow[t]{6}{*}{5.6} & \multirow[t]{6}{*}{5.9} & 6.0 & 26.6 & 28.6 & 56.2 & 58.4 \\
\hline & & & 4.6 & 21.3 & & 58.1 & 58.0 \\
\hline & & & 5.6 & & & 60.6 & \\
\hline & & & 4.7 & & & 56.9 & \\
\hline & & & 4.7 & & & 56.5 & \\
\hline & & & 4.4 & & & 57.6 & \\
\hline
\end{tabular}




\section{Figures}
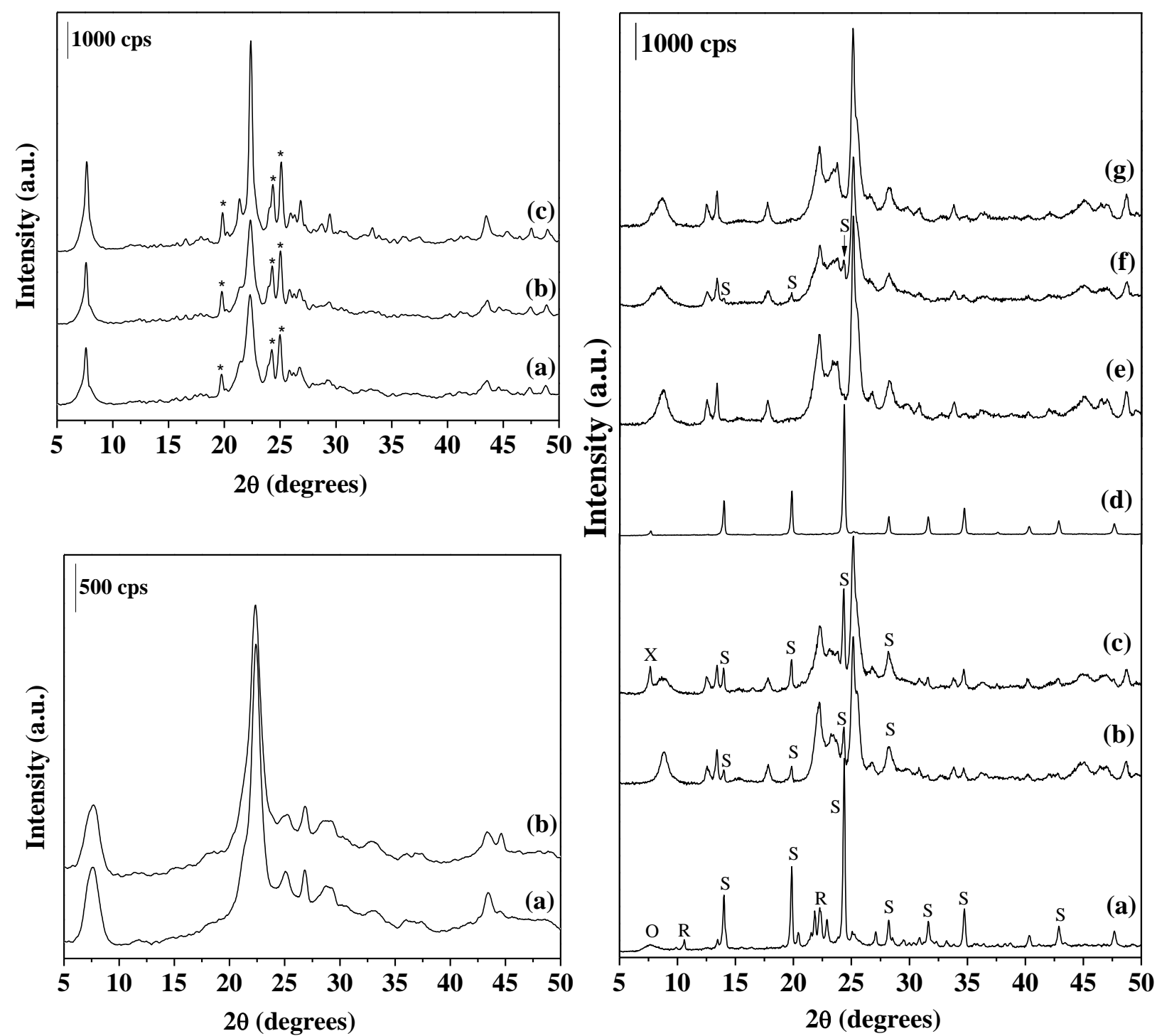

Figure 1. Top-left: Powder XRD patterns of samples obtained from gels with only $\mathrm{Et}_{6} \mathrm{DQ}_{5}$ and different $\mathrm{Si} / \mathrm{Al}$ molar ratios: (a) $0.54 \mathrm{Et}_{6} \mathrm{DQ}_{5} / 15$, (b) $0.54 \mathrm{Et}_{6} \mathrm{DQ}_{5} / 10$ and (c) $0.54 \mathrm{Et}_{6} \mathrm{DQ}_{5} / 8$ (peaks marked with $*$ correspond to an unidentified phase). Bottom-left: samples obtained with pyrrole and tert-butylamine as co-SDAs: $0.27 \mathrm{Et}_{6} \mathrm{DQ}_{5}$ 0.27 pyrrol/15 (a) and $0.27 \mathrm{Et}_{6} \mathrm{DQ}_{5}-0.27$ tertbutyl/15 (b), after 14 days of hydrothermal treatment. Right: samples obtained with TMA as co-SDA: (a) $0.27 \mathrm{Et}_{6} \mathrm{DQ}_{5}-0.27 \mathrm{tma} / 15$, 
(b) $0.27 \mathrm{Et}_{6} \mathrm{DQ}_{5}-0.27 \mathrm{tma} / 15 \mathrm{EHF}$, (c) $0.405 \mathrm{Et}_{6} \mathrm{DQ}_{5}-0.135 \mathrm{tma}^{2} 15$, (d) $0.27 \mathrm{Et}_{6} \mathrm{DQ}_{5}-$ $0.27 \mathrm{tma} / 10$, (e) $0.27 \mathrm{Et}_{6} \mathrm{DQ}_{5}-0.27 \mathrm{tma} / 10 \mathrm{EHF}$, (f) $0.27 \mathrm{Et}_{6} \mathrm{DQ}_{5}-0.27 \mathrm{tma} / 8$ and $(\mathrm{g})$ $0.27 \mathrm{Et}_{6} \mathrm{DQ}_{5}-0.27 \mathrm{tma} / 8 \mathrm{EHF}$, after 14 days of hydrothermal treatment. $\mathrm{S}=\mathrm{SOD}, \mathrm{R}=$ RUT, $\mathrm{O}=\mathrm{OFF}$ and $\mathrm{X}=$ undefined phase. 

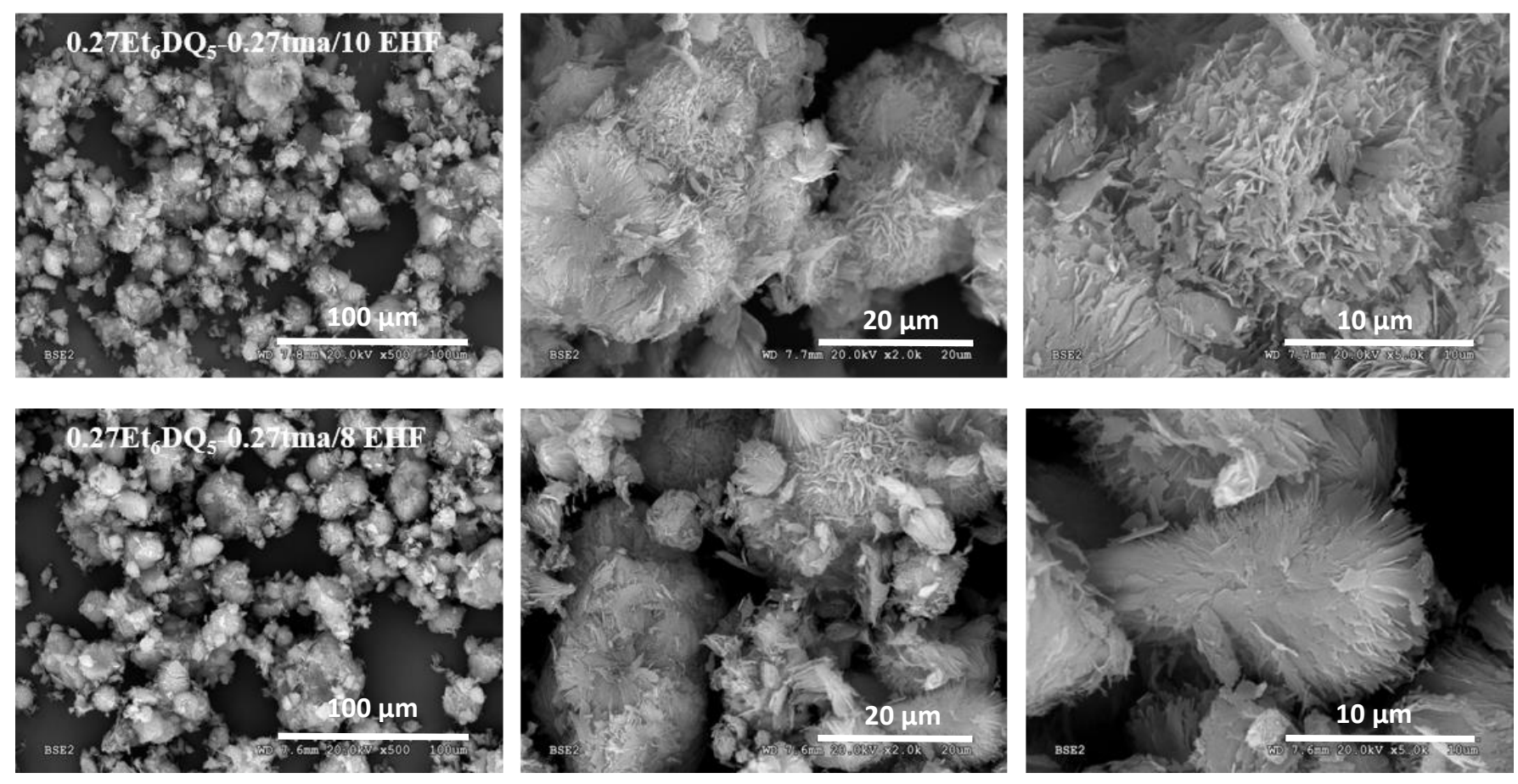

Figure 2. FESEM pictures of $0.27 \mathrm{Et}_{6} \mathrm{DQ}_{5}-0.27 \mathrm{tma} / 10 \mathrm{EHF}$ (top) and $0.27 \mathrm{Et}_{6} \mathrm{DQ}_{5}$ 0.27tma/8 EHF (bottom) samples. 


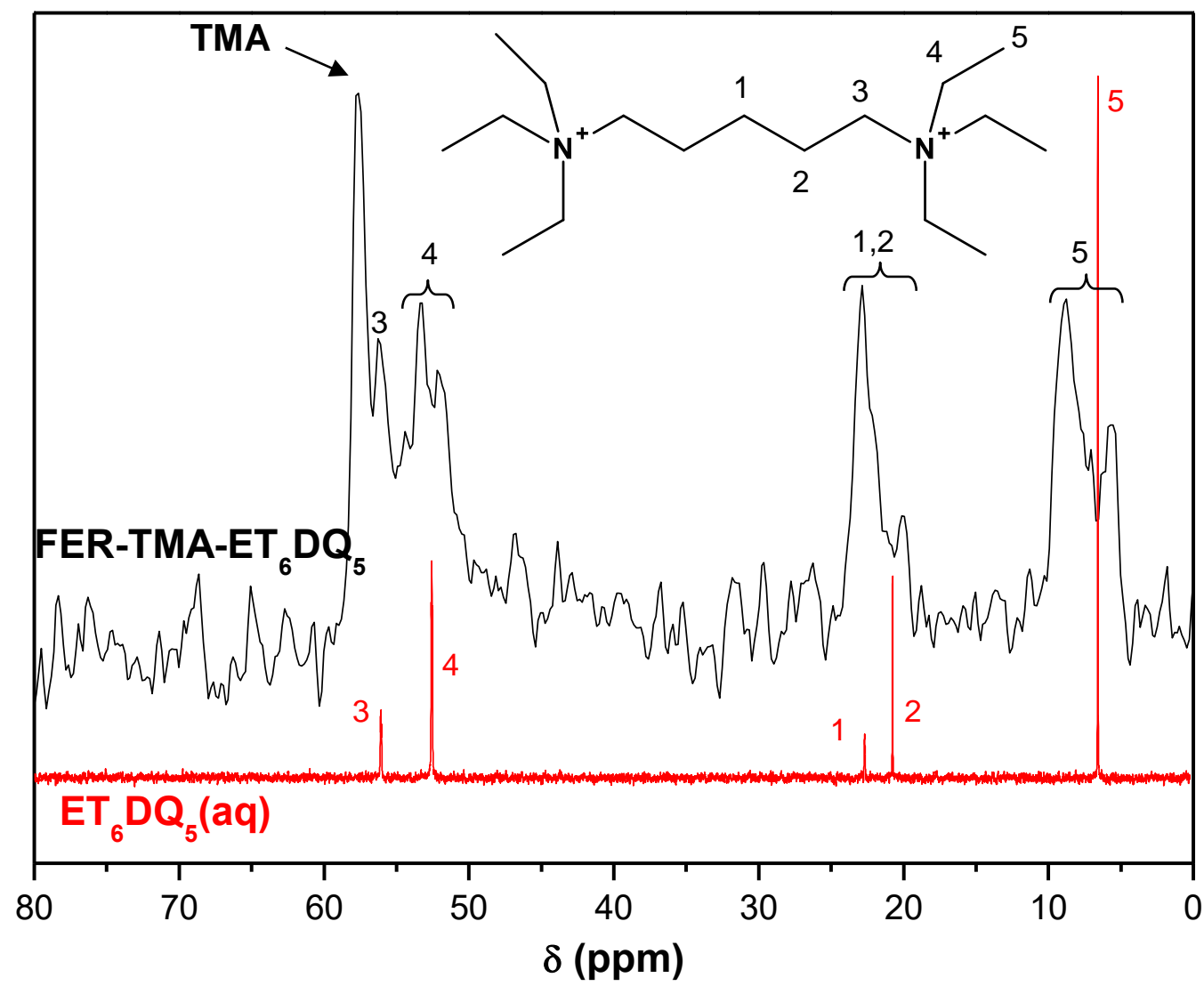

Figure 3. ${ }^{13} \mathrm{C}$ NMR spectra of FER-TMA-Et $5 \mathrm{DQ}_{5}$ sample (top, black line) and of an $\mathrm{Et}_{6} \mathrm{DQ}_{5}$ aqueous solution (bottom, red line). 

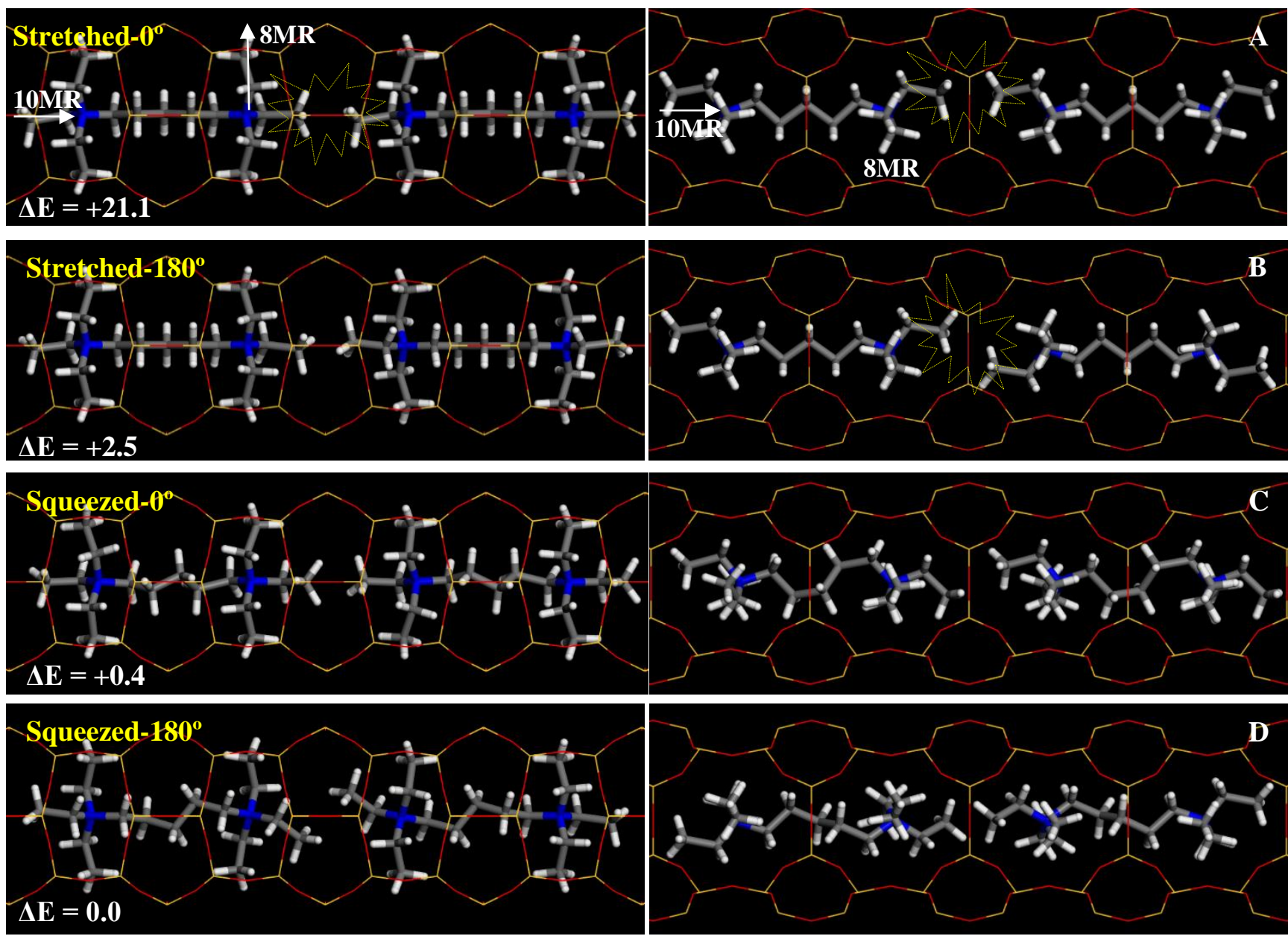

Figure 4. Possible arrangements and orientations of $\mathrm{Et}_{6} \mathrm{DQ}_{5}$ dications in the FER framework, as calculated by Dreiding methods. 

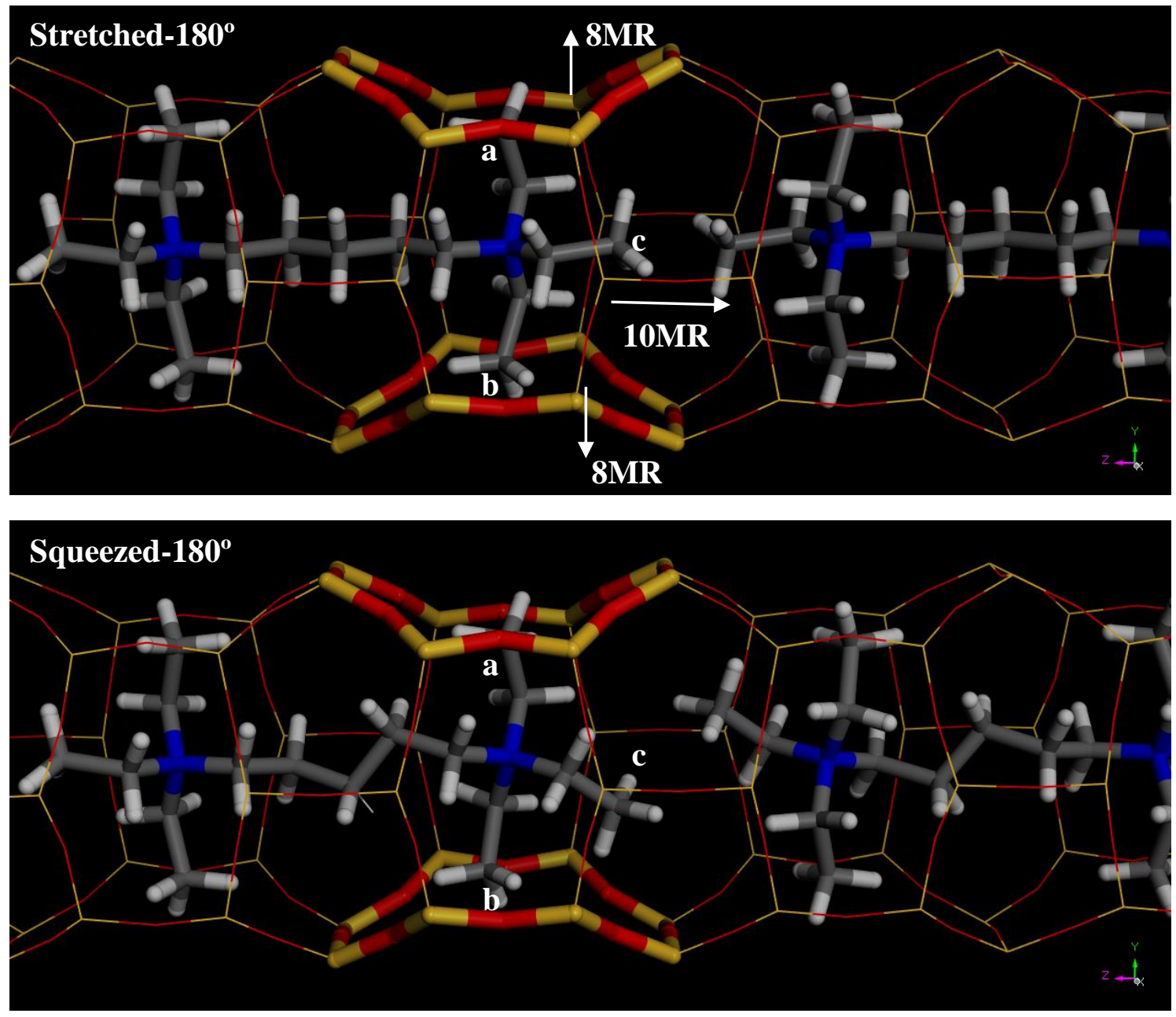

Figure 5. Detail of the location of triethylammonium groups in the FER framework, with two of the ethyl arms ('a' and 'b') aligned with the 8MR channels, and the other ('c') aligned with the $10 \mathrm{MR}$ channels, with $\mathrm{Et}_{6} \mathrm{DQ}_{5}$ dications in 'stretched-180' (top) or 'squeezed-180' (bottom) configurations. 

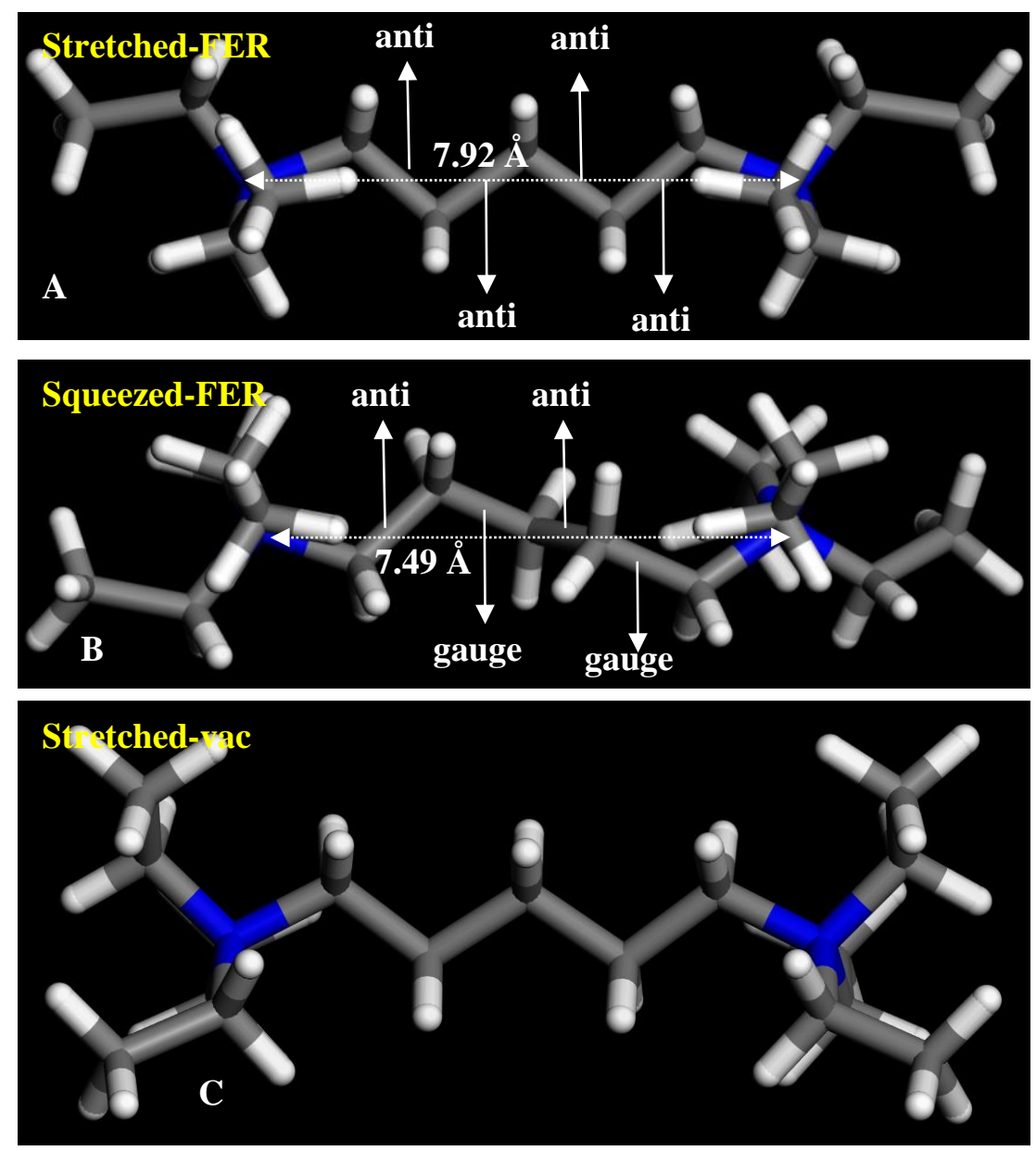

Figure 6. Detail of the two different conformations of $\mathrm{Et}_{6} \mathrm{DQ}_{5}$ dications in the FER framework ('A' and 'B'), and the most stable conformation in vacuum ('C'). 


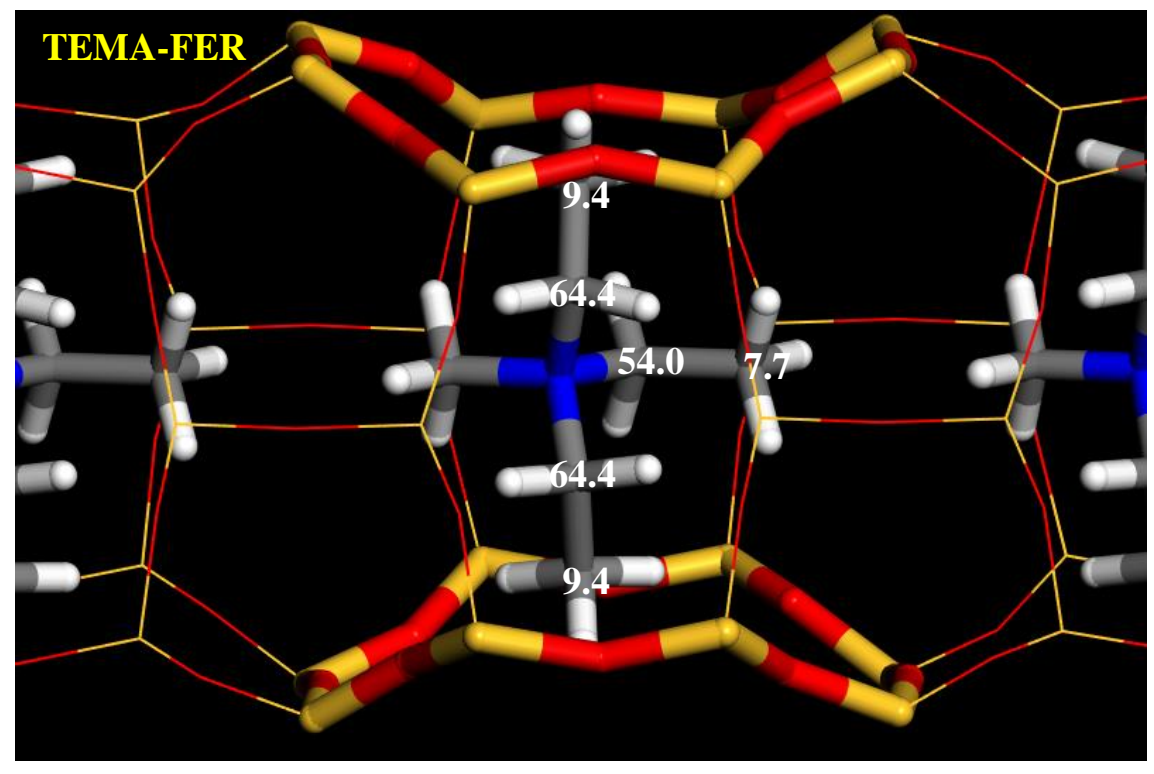

Figure 7. Detail of the location of TEMA cations in the FER framework, with the corresponding theoretical ${ }^{13} \mathrm{C}$ NMR chemical shifts as a function of the ethyl group location. 


\section{References}

[1] L. Gómez-Hortigüela, M. A. Camblor, Struct. Bonding 175 (2018) 1-41.

[2] J. L. Casci, B. M. Lowe, T. V. Whittam, Eur. Patent 42226A1 (1981).

[3] J. L. Casci, B. M. Lowe, T. V. Lowe, US Patent 4836996 (1989).

[4] J. L. Casci, A. Stewart, Eur. Patent 377291 (1990).

[5] B. Han, S. Lee, C. Shin, P. a Cox, S.B. Hong, Chem. Mater. 17 (2005) 477-486.

[6] P. Caullet, J. L. Paillaud, A. Simon-Masseron, M. Soulard, J. Patarin, Comptes Rendus Chim. 8 (2005) 245-266.

[7] M. Moliner, F. Rey, A. Corma, Angew. Chem. Int. Ed. 52 (2013) 13880-13889.

[8] M. J. Díaz-Cabañas, M. A. Camblor, Z. Liu, T. Ohsuna, O. Terasaki, J. Mater. Chem. 12 (2002) 249-257.

[9] A. Moini, K. D. Schmitt, E. W. Valyocsik, R. F. Polomski, Zeolites 14 (1994) 504511.

[10] A. Jackowski, S. I. Zones, S. J. Hwang, A.W. Burton, J. Am. Chem. Soc. 131 (2009) 1092-1100.

[11] M. Moliner, M. J. Díaz-Cabañas, V. Fornés, C. Martínez, A. Corma, J. Catal. 254 (2008) 101-109.

[12] P. Caullet, J.-L. Paillaud, Y. Mathieu, N. Bats, Oil Gas Sci. Technol.-Rev. l'IFP. 62 (2007) 819-825.

[13] J. H. Lee, M. B. Park, J. K. Lee, H.-K. Min, M. K. Song, S. B. Hong, J. Am. Chem. Soc. 132 (2010) 12971-12982.

[14] S. H. Lee, C. H. Shin, D. K. Yang, S. D. Ahn, I. S. Nam, S. B. Hong, Microporous Mesoporous Mater. 68 (2004) 97-104. 
[15] A. Corma, M. J. Díaz-Cabañas, J. L. Jordá, C. Martínez, M. Moliner, Nature 2006, $443,842-845$.

[16] P. Lu, L. Gómez-Hortigüela, L. Xu, M. A. Camblor, J. Mater. Chem. A 6 (2018) $1485-1495$.

[17] P. Lu, L. Gómez-Hortigüela, M. A. Camblor, Chem.-Eur. J. 25 (2019) 1561-1572.

[18] P. Lu, A. Mayoral, L. Gómez-Hortigüela, Y. Zhang, M. A. Camblor, Chem. Mater. 31 (2019) 5484-5493.

[19] S.-H. Lee, C.-H. Shin, G. J. Choi, T.-J. Park, I.-S. Nam, B. Han, S. B. Hong, Microporous Mesoporous Mater. 60 (2003) 237-249.

[20] S. B. Hong, Catal. Surv. Asia 12 (2008) 131-144.

[21] A. B. Pinar, L. Gómez-Hortigüela, J. Perez-Pariente, Chem. Mater. 19 (2007) 56175626.

[22] R. García, L. Gómez-Hortigüela, I. Díaz, E. Sastre, J. Pérez-Pariente, Chem. Mater. 20 (2008) 1099-1107.

[23] A. B. Pinar, L. Gómez-Hortigüela, L.B. McCusker, J. Pérez-Pariente, Chem. Mater. 25 (2013) 3654-3661.

[24] R. K. S. Almeida, L. Gómez-Hortigüela, A.B. Pinar, J. Peréz-Pariente, Microporous Mesoporous Mater. 232 (2016) 218-226.

[25] S. F. Abdo, S. T. Wilson, Zeolites in industrial catalysis. J. Cêjka, R. Morris, P. Nachtigall (Eds.), Zeolites in Catalysis: Properties and Applications, vol. 28, RSC Catalysis Series (2017) 310-350.

[26] B. Bernardo-Maestro, P. Gálvez, D. González, F. López-Arbeloa, J. Pérez-Pariente, L. Gómez-Hortigüela, J. Phys. Chem. C 122 (2018) 20377-20390. 
[27] M. G. O'Brien, A. M. Beale, C. R. A. Catlow, B. M. Weckhuysen, J. Am. Chem. Soc. 128 (2006) 11744-11745.

[28] D. Nieto, J. Pérez-Pariente, E. Toran, F. López-Arbeloa, L. Gómez-Hortigüela, Microporous Mesoporous Mater. 287 (2019) 56-64.

[29] P. Lu, L. Gómez-Hortigüela, Z. Gao, M. A. Camblor, Dalton Trans. 48 (2019) 17752-17762.

[30] Forcite Module, Material Studio 2017 R2, BIOVIA.

[31] S. L. Mayo, B. D. Olafson, W. A. Goddard, J. Phys. Chem. 94 (1990) 8897-8909.

[32] S. J. Clark, M. D. Segall, C. J. Pickard, P. J. Hasnip, M. J. Probert, K. Refson, M. C. Payne, Kristallogr. 220 (2005) 567-570.

[33] J. P. Perdew, K. Burke, M. Ernzerhof, Phys. Rev. Lett. 77 (1996) 3865-3868.

[34] C. J. Pickard, F. Mauri, Phys. Rev. B 63 (2001) 63245101.

[35] M. L. Occelli, A. J. Perrotta, ACS Symp. Ser. Am. Chem. Soc. (1983) 21-39.

[36] M. B. Park, S. J. Cho, S. B. Hong, J. Am. Chem. Soc. 133 (2011) 1917-1934.

[37] B. Marler, H. Gies, Zeitschrift Fur Krist. - Cryst. Mater. 230 (2015) 243-262.

[38] M. P. Attfield, S. J. Weigel, F. Taulellec, A. K. Cheetham, J. Mater. Chem. 10 (2000) 2109-2113. 